\title{
DIE SAMEWERKING TUSSEN PREDIKANT, KERKRAAD EN ORRELIS').
}

Oor die aktualiteit van ons onderwerp sal daar onder ons seker wel geen verskil van mening bestaan nie. Die amp van die bedienaar van die woord, die verantwoordelikheid van die kerkraad en die taak van die orrelis, hoewel elk sy besondere roeping ten opsigte van die erediens het, staan intussen tog nie los en onafhanklik van mekaar nie en het nie maar insidentele aanrakingspunte met mekaar nie, maar moet doelgerig met mekaar saamwerk waar die gemeente byeenkom om God te ontmoet en te verheerlik. Die erediens met sy verskillende bestanddele moet 'n harmoniese eenheid vorm en daarom, terwille van die goeie gang van sake, moet die predikant, die kerkraad en die orrelis in noue voeling met mekaar staan. ${ }^{2}$ ) $\mathrm{Om}$ ' $n$ baie eenvoudige voorbeeld te gebruik, as dit Paassondag is, moet die predikant oor die opstanding van Christus preek, die kerkraad moet o.m. toesien dat dit wel gebeur en die orrelis moet die keuse van sy stukke op die bepaalde preekstof betrek. As ons die volgorde: predikant, kerkraad en orrelis, soos die onderwerp aandui, behou, moet ons ons vereers bepaal by die vraag wat die roeping van die voorganger by die erediens is.

$\mathrm{Hy}$ is voor alles bedienaar van die Woord, m.a.w. hy tree as geakkrediteerde gesant van God op wat die wil van God (soos dit in die heilige Skrif geopenbaar is, aan die gemeente verkondig. Ons mag as axioma aanvaar dat dit die wil van God is om deur die verkondiging van Sy Woord Sy duurgekoopte gemeente te bewaar, te versterk en uit te brei. Die prediker is dus gebonde aan die heilige Skrif, wat die boodskap bevat wat hy aan die gemeente moet oorbring. Deur midde] van die verkondiging van die Woord kom God na ons toe; en nou is dit van belang om te onthou dat hierdie Woord van God primêr die openbaring is van God in Christus Jesus, die vleesgeworde Woord. ${ }^{3}$ )

1) Lesing gehou by 'n kongres van die Raad vir Kerkmusiek te Krugersdorp, April 1953. Dis vir my nie heeltemal duidelik waarom die Raad vir Kerkmusiek my juis die vererende opdrag gegee het om oor die onderwerp: "Die samewerking tussen predikant, kerkraad en orrelis" te praat nie. Liewer sou ek gesien hat dat hierdie taak aan bevoegder hande toevertrou was, wat ek dan ook sonder versuim en hoopvol voorgestel het, maar my besware is nie van genoegsame gewig beskou om my van hierdie opdrag te onthef nie. Ek wil dan ook dadelik begin met te sê, om ewentuele teleurstelling te voorkom, dat u nie 'n uitgewerkte, akademiese betoog moet verwag nie, maar eenvoudig die beskouinge van 'n dorpspredikant wat tussen veelsoortige ampspligte in en interrupsies en afwesigheid van huis 'n geleentheid probeer vind het om 'n bietjie oor die kwessie na te dink. Ek gebruik did woord erediens dwarsdeur in die betekenis wat onder ons algemeen gebruiklik is.

2) Die enigste kontak, soos iemand opgemerk het, tussen predikant en orrelis bestaan dikwels net uit die gesangbriefie wat voor elke diens aan die orrelis gestuur word. Van kontak tussen kerkraad en orrelis is daar in die reël ewemin sprake.

3) J. J. STAM, Rondom de Preek, 1946, bls.18. 
Dit beteken dat die boodskap wat die prediker bring, nie in abstrakte gedagtes bestaan nie, maar dat hy Christus Jesus verkondig. Die Bybel is die getuienis van die openbaring van God in Christus Jesus, en in Christus Jesus buig God Hom na ons toe neer en ontmoet ons. Die inhoud van die prediking is die heil in Christus Jesus, in al die onuitputlike volheid daarvan, vir die mens wat deur die sonde van God losgeskeur en weggeslinger is. Om saam te vat: die prediking geskied in opdrag; die prediker kom met 'n heilsboodskap wat hom toevertrou is; hy tree amptelik as gesant op, m.a.w. dwarsdeur val die aksent op sy roeping en sending-die prediker is 'n geroepene en gestuurde.

In verband hiermee is dit nou van belang om die vraag na die doel waar die gemeente voor saamkom, kortliks na te gaan. ${ }^{4}$ Die populêre voorstelling is, dat ons Sondae kerk toe kom om geestelike voedsel te ontvang, plat uitgedruk: om padkos te kry; om gestig, d.w.s. opgebou te word in ons geloof; om iets vir die komende week saam huis toe te neem. Buitekant die kerkdeure wag immers die lewe met sy onafwysbare, harde werklikheid vir ons, en ons moet ons deur die lewe heen worstel, met sy stryd en benouenis. Volgens hierdie opvatting is dit duidelik dat die preek die allesbeheersende in die erediens is en alles om die preek sentraliseer. Weer ander meen dat ons kerk toe kom omdat God ons roep om te hoor wat Hy vir ons, gebroke mensekinders, te sê het. Ons kom dan nie in die eerste plek om sielespys te ontvang of om God in ons samekoms te loof en te prys nie, maar wel om te luister en die gepredikte Woord in ons lewe te laat geld. Volgens hierdie mening is die kerkgang dus in die grond van die saak 'n daad van gehoorsaamheid aan God. In albei beskouinge lê daar 'n element van waarheid opgesluit. Maar daar is ook nog 'n derde antwoord op die vraag, en hier word die klem op die woord erediens gelê. Die gemeente kom nie alleen saam om 'n versterkende woord te hoor of net gehoorsaam te luister nie. Daar is meer. In die samekoms van die gemeente, soos ek reeds opgemerk het, ontmoet God Sy volk en ontmoet die volk van God hulle God. Sodra die votum uitgespreek is, is die individue wat byeen gekom het, gestempel tot gemeente van Jesus Christus, saamvergader tot eer van God. Alle handelinge in hierdie diens moet dan ook gerig wees op die verheerliking van God. Daarom pas die naam erediens hier so mooi. Volgens hierdie sienswyse is die preek in die erediens, hoe belangrik owerigens ook, 'n onderdeel van die geheel, m.a.w. die erediens in sy geheel is hoofsaak en nie die preek op homself sonder meer nie. Die preek staan in diens van die erediens, maar net so ook alle ander handelinge: Skriflesing, gebed, smeking, danksegging, offergawe, ook die lied wat gesing

4) Id., bls. 42v.v. Vgl. TH. L. HAITJEMA, Nederl. Herv. Kerkrecht, 1951, bls. 227v. 
word en die aandeel wat die orrelis in die erediens het. Dit alles moet een welluidende eenheid tot verheerliking van God vorm.

Onder die verskillende samestellende dele waaruit die erediens bestaan, neem die bediening van die Woord uit die aard van die saak 'n belangrike plek $i^{5}$ ) en hiermee moet wat uit die Skrif voorgelees word, in ooreenstemming wees, so ook die keuse van die psalms en gesange. $\left.{ }^{6}\right)$ Die predikant wat die kruisiging van Jesus behandel, sal tog sekerlik nie die opstandingshoofstuk uit die Korinthiërbrief gaan voorlees nie en ook nie psalms of gesange laat sing wat nie met die lydenstof ooreenkom nie. Ook die orrelis moet hier rekening mee hou en nie die gemeente by so 'n geleentheid verras met die "Halleluja-koor" uit die Messias nie. In hierdie verband verdien die vraag miskien ook wel oorweging, nl. of dit nie wenslik is nie, as dit ten minste prakties uitvoerbaar is, dat die orrelis vooraf 'n aanduiding kry waaroor die preekstof gaan; hy kan dan sy slotstuk by die uitgaan van die kerk laat aansluit by die preek en die hart van die gemeente deur sy spel nogeens ophef tot God. Wat my betref, ek sit graag by die uitgaan van die kerk nog 'n rukkie en luister na die orrelspel. As dit goed is, kan hierdie slotstuk, om dit so uit te druk, die seël op die verrigtinge druk. Ons kan dit nie ontken nie dat die gewyde toonkuns, wanneer dit in die diens van God staan, die mag van die gewyde woord wel deeglik ondersteun. Maar hier is ' $n$ woordjie van waarskuwing miskien nodig. Die orrelis moet hom nie allereers kunstenaar voel nie, maar dienaar van God, en deurdring wees van die roeping om die heilige deur die skone, of beter nog, om God deur die kuns te dien. ${ }^{T}$ )

Hoe pas die kerkraad in hierdie raamwerk? Op die kerkraad rus 'n veelvoudige verantwoordelikheid. In die algemeen kan ons sê dat die kerkraad insonderheid moet toesien dat die Woord van God suiwer verkondig, die sakramente volgens die instelling van Christus bedien en die christelike dissipline gehandhaaf word, en verder dat hy hom moet beywer vir wat in die algemeen vir die welwese van die gemeente bevorderlik is. Onder hierdie menigerlei pligte val seker ook die

5) VAN DER LEEUW ontsê m.i. ten onregte aan die prediking die prominente plek wat dit in die erediens toekom, as hy beweer: „De liturgie wordt niet vastgesteld in verband met de preek, doch omgekeerd. De liederen worden niet gekozen als passende omlijsting van de preek, maar vormen de zelfstandige lofprijzing der gemeente. De schriftlezing is niet de aanduiding van het textverband, maar de periodieke lezing van het Woord Gods, die haar gang gaat, los van de preek, en waarnaar deze zich richten kan." Dit is reggesit deur PH. HuYser, De Paraenese in de Prediking, 1941, bls. 122. Ek stem met HUYSER saam, dat die sentrale punt in die erediens die prediking van die Woord is, met hierdie voorbehoud, dat die homileet die liturg nie heeltemal mag oorskadu nie.

6) Vgl. J. J. VAN OOSTERZEE, Practische Theologie, dl. II, 1878, bls. 76, §4.

7) „De gewijde kunst moet als een heilige Christophorus zijn, die zijne "edelste krachten aan den dienst van het Heilige wijdt." VAN OOSTERZEE, a.w. bls. 35 . 
sorg van die gemeentelike sang wat nie maar sonder meer op die skouers van die predikant of selfs van die orrelis afgeskuiwe behoort te word nie. Ek dink stellig dat dit in die weg van hierdie opsieners van die gemeente lê om hulle in die gemeentelike sang te interesseer en om aan te stuur op verbetering daarvan, want ook die lied, wat 'n onafskeidbare bestanddeel van die erediens vorm, moet dien tot verheerliking van God. Dit hoort tog nie so, dat die kerkraad maar lydelik toesien dat die gemeente gebrekkig sing nie. ${ }^{8}$ ) $\mathrm{Ek}$ wil my nou nie graag aan liefdelose kritiek skuldig maak en ook nie gevoelige nature aanstoot gee nie maar meer as eenmaal as 'n mens na die gemeentelike sang luister kom 'n ernstige woord uit die Skrif in jou gedagte. In die dae van Amos het God vir die volk van Israel deur die profeet laat weet: „Verwyder van My die geraas van jou liedere! En na die geluid van jou harpe wil Ek nie luister nie", 5:23. Die sang van die volk word hier veragtelik 'n .geraas" genoem. Met hierdie woorde wil die Here aantoon, volgens die ou Bybelverklaarder KLINKENBERG, ,dat hun gezang Hem even zoo walgelijk was, als een woest getier van razende menschen". ${ }^{9}$ ) Dit het niks gemeen gehad met die heerlike sang en spel in die tempel van Jerusalem, soos Dawid dit oorspronklik tot eer van God georganiseer het nie.

Hoe ongelooflik dit ook mag skyn, is dit tog wel 'n feit dat die eer van God nie altyd in ons kerklied beoog word nie. Daar word maar gesing, omdat die predikant volgens die orde van die diens ..'n versie opgee". Dis sleurwerk; die hart sit nie daarin nie; sommige is belangeloos en sing nie saam nie, omdat hulle die melodie nie ken nie en nie geïnteresseerd genoeg daarin is om dit aan te leer nie, terwyl ander weer wel sing, maar heeltemal gedagteloos; sommige veroorloof hulle wonderlike, wydlopige sypaaie wat die melodie nie voorskrywe nie, en ander kan maar weer van die noot waar hulle mee besig is, nie afskeid neem nie; terwyl sommige binnensmonds sing, meen ander weer "hoe harder hoe mooier"! Kortom, die geheel vorm inderdaad 'n wanklank en ' $n$ mens is soms maar dankbaar as die "versie" uit it. ${ }^{10}$ ) As dit nou vir ons self nie mooi klink nie en vir die liturgiese gevoel nie verheffend is nie kan dit tog in die oor van God wie se diens die hoogste en beste van ons verg, sekerlik nie welluidend wees nie.

8) ,Met die verbetering van die gemeente se sang word die vatbaarheid van die gemeente vir die evangeliieboodskap ook verhoog," P. J. LooTs, Ons Kerklied deur die Eeue, 1948, bls. 261.

9) J. VAN NUYS KLINKENBERG, De Bijbel, ens., 1788, dl. XVII, bls. 55.

10) Die kerksang was vroeër ook nie altyd onberispelik nie, helaas! VaN IPEREN beskrywe die manier van sing in sy dae as volg: „De noten onnodig rekken, in den mond te draayen, te kaauwen en door ettelijke verlagingen en verheffingen tusschen de tanden en het gehemelte slangsgewys henen te slingeren en te dwarrelen, gelijk tot hiertoe de meste algemeene, doch belachelijke gewoonte geweest was," gesit. deur H. H. BARGER, Ons Kerkboek, 1900, bls. 60 . 
Intussen moet ons hier teen uiterstes waak, want aan die ander kant, hoe skoon daar ook gesing mag word en hoe onberispelik daar aan die eise van sang - en toonkuns voldoen mag word, as die hart nie in die lied klink nie, is ook dit nie 'n aanneemlike offer in die oog van God nie. Ek kom terug op die aanhaling uit Amos van soëwe. lemand het êrens in verband met hierdie woorde opgemerk, dat dit 'n waarskuwing vir almal bevat wat meen dat hulle God deur pragtige musiek in Sy huis kan behaag, terwyl hulle daar ondertussen nie aan dink om Hom in hulle hart te aanbid en in hulle daaglikse lewe te gehoorsaam nie. Ons mag hierdie opmerking wel ter harte neem. Die apostel vermaan ons ook om tot eer van God in ons hart te sing, wat sekerlik ook insluit dat die hart, d.w.s. die liefde tot God, in die lied moet klop. Die hart moet met die mond saamstem, sê Augustinus.

Ook die aanstelling van orreliste berus by die kerkraad. ${ }^{11}$ ) Oënskynlik lyk dit 'n geringe saak wat nie hoofbrekens behoef te besorg nie, maar die ervaring het ons geleer dat dit in die reël nie so eenvoudig gaan nie, want afgesien nog van die feit dat daar 'n skreiende tekort aan orreliste is, is nie elkeen wat musiek ken, op grond daarvan sonder meer as orrelis bevoeg nie.

Vereers kom die persoon van die applikant self in aanmerking. Hoedanig is sy wandel? Is hy iemand wat hom kan inlewe in die karakter en aard van die christelike erediens? Is daar geestelike verwantskap tussen hom en die lied wat hy tot eer van God moet vertolk? Bestaan miskien die gevaar dat alles in die erediens buite hom sal omgaan en hy sy werk dus bloot meganies sal verrig, sonder besieling, sonder wyding? Kortom, kan hy agter die orrel saam met die gemeente aanbid, smeek, danksê, jubel, en in sy spel die innerlike roersele van die godvrugtige siel weergee? Ek dink ons kan dit as vanselfsprekend beskou, dat die religieuse waarde van die orrel afhang van die hand waaraan dit toevertrou is. Die orrelis se hart moet in sy werk sit. lemand kan onberispelik van wandel en professioneel goed gekwalifiseer wees en tog die vermoë mis om hom in te lewe in die atmosfeer van die christelike erediens. ${ }^{12}$ )

Verder moet die kerkraad aandag gee aan die musikale bevoegdheid van die applikant. Is hy professioneel opgewasse teen die eise wat billikerwyse aan hom gestel sal word? Hierby kom nog die oorweging-ek het reeds daarop gewys - of die orrelis sy taak uit liefde vir sy roeping vervul en uit 'n begeerte om langs hierdie weg sy deel by te dra om deur die talente wat God aan hom toevertrou het, in die

11) Kerkwet van die Ned. Herv. Kerk van Afrika, 1951, Art. 5.

12) In sy Ons Kerkboek haal BARGER voorbeelde aan van ,ongepaste opsieringen van het kerkgezang" wat orreliste hulle in vroeër dae weleens veroorloof het, bls. 60v. Vgl. K. R. HAGENBACH, Grundlinien der Liturgik und Homiltik, 1863, bls. 57 . 
erediens God te verheerlik, of is dit dalk uitsluitend 'n kwessie van om den brode?

Daar is, helaas! 'n baie groot gebrek aan goed opgeleide orreliste in ons kerk, net soos in ander kerke ook, en meer as een kerkraad moet genoeë neem met gewillige maar onbekwame kragte. As die goeie wil aan weerskante egter daar is en die regte gesindheid, hoef hierdie beswaar nie onoorkoomlik te wees nie, want as die orrelis sy werk liefhet en God daardeur wil eer, sal hy behoefte daaraan voel om hom deur gereelde, al is dit dan ook moeisame, oefening self àl beter te bekwaam. Ek het telkens baie sterk nadruk daarop gelê, dat daar by die orrelis veral liefde vir sy roeping moet wees, maar nou wil ek met nie minder klem nie daarop wys, dat die orrelis van hierdie liefde alleen nie kan lewe nie en dat dit eweseer tot die pligte van die kerkraad behoort om vir ' $n$ behoorlike besoldiging van sy orrelis te sorg, gedagtig aan die Skrifwoord dat wie spaarsaamlik saai, ook spaarsaamlik maai. ${ }^{13}$ )

Ons het nou al langsamerhand by die orrelis gekom oor wie ek reeds uit die aard van die saak een en ander gesê het. As ons aanneem dat die lofprysing van God in ons erediens dié waardering moet vind wat dit verdien, voel ons meteens dat die orrelis, hoewel sy funksie nie 'n kerklike ,bediening" in die volle kerkregtelike sin van die woord is nie, nietemin 'n hoogs belangrike taak vervul. 'n Orrelis veronderstel 'n orrel. Daar was 'n tyd, en nou dink ek aan die $17 \mathrm{de}$ eeu, toe die kerkorrel as 'n gevreesde werktuig van die Vors van die duisternis voorgestel is. ${ }^{14}$ ) Selfs 'n vername godgeleerde soos VoETIus was 'n oortuigde en konsekwente teenstander teen die invoering van die orrel in die kerk. Sy gevoele was dat orrelmusiek geen deel of toevoegsel van die openbare erediens uitmaak nie. Maar Voetius en sy geesverwante was in die minderheid. In manne soos Constantyn HuYgens het die kerkorrel warm pleitbesorgers gehad, natuurlik egter met dien verstande dat die orrel, om in die taal van Huygens te praat, nie ,louter tot vermaak van de gemeente" bespeel sou word nie. Tereg het hy daarop gewys dat dit nie alleen wenslik is dat die sang van die gemeente deur die orrel begelei word nie, maar ook, om sy woorde te gebruik, ,.dat het orgel . . . vooruit een stukje inleiding tot het gezang maakte, om niet de stemmen der gemeente alleen, maar zelfs hare har-

13) In 'n belangrike artikel oor ,Sang en Musiek in ons Kerk" in die Sondagnuus, d.d. 16 Nov. 1947, merk STEVE DE VILLIERS in hierdie verband op ,dat die salarls wat dikwels deur ons kerkrade aan orreliste aangebied word, nie juis daartoe bydra om die geskikste persone te trek nie."

14) "In den gereformeerden eeredienst heeft het zeer lang geduurd voor men het orgel ter begeleiding van den gemeentezang wilde toelaten," G. VAN DER LeEUW, Wegen en Grenzen, 2de dr., 1948, bls. 386, Vgl. ook G. D. J. SCHоTEL, De Openbare Eerediens der Nederl. Herv. Kerk, 2de dr., 8.j., bls. 62 . 
ten te helpen bereiden tot die zedige en eerbiedige aandacht die in 't uitspreken van 't heilige Woord vereischt werd". ${ }^{15}$ )

Ook in ons land was die orrel aanvanklik nie in alle gemeentes ewe welkom nie en daar bestaan meer as een vermaaklike staaltjie, waaruit blyk watter onverhole weersin meer as een oudste in Israel teenoor die orrel gekoester het. Hier en daar het selfs 'n dramatiese botsing ontstaan tussen die gevestigde voorsanger en die nuwe mededinger. Natuurlik, as die orrel die erediens vir homself opeis en dit domineer, moet hy taktvol maar beslis na sy regmatige plek terugverwys word, want die kerkgebou is nie 'n konsertsaal nie en die erediens is nie daar terwille van die verheerliking van die toonkuns nie. Maar nou moet ons darem ook hier weer nie in uiterstes verval nie. Die predikant wat geen gevoel vir musiek het nie en die kerkraad wat in hierdie opsig sy armoede met hom deel, moet nou hieruit nie dalk die gevolgtrekking maak, dat die orrel maar soveel as moontlik moet swyg en die begeleiding van die sang van die gemeente tot ' $n$ minimum beperk word nie, dus veral geen voor en naspele nie. Dit sou 'n miskenning van die plek van die toonkuns in die diens van God beteken. Maar aan die ander kant moet die kunsliewende predikant en die gelykvoelende kerkraad ook nie van die orrelis telkens 'n vermomde orreluitvoering tydens die erediens verwag nie, want dit sou weer in stryd met die aard en doel van die christelike erediens wees.

Niemand sal my seker weerspreek, as ek konstateer dat ons orreliste in die verlede dikwels 'n ondankbare werk verrig het en nie die waardering ontvang het waarop hulle geregtig was nie, ook nie op stoflike gebied nie. Selfs nou nog word die taak en die plek van die orrelis in die erediens nie altyd en nie in wye kring verstaan nie. Die orrelbegeleiding van die sang word deur baie beskou as 'n bykomstigheid, dikwels meer verduur as gewaardeer; ô en hòe daar gespeel word, maak nie eintlik saak nie; die aangrypende woorde van die besielde psalmdigter vind in menige hart weinig of geen weerklank nie :

Sing vrolik, hef die stem na bowe;

regverdiges, verhef die HEER!

Dit pas opregtes God te lowe

en uit te jubel tot Sy eer.

Laat die psalmgesange -

stem van sterk verlange

om die HeEr te dank -

by die smeltend-skone

harp- en sitertone,

liefde-en lof verklank!

15) Schotel, a.w., bls. 66. 
Intussen stem dit tog ook weer tot dankbaarheid dat daar wel tekens is, dat ons kerk begin insien dat ons ons sang inderdaad moet verbeter ${ }^{16}$ ) en in verband hiermee ook orreliste van kerkweë moet oplei en daarby bete: as voorheen besoldig. Dat dit sal geskied, is vir ons kerk van groot belang, en ons mag verwag dat hierdie ontwakende belangstelling geleidelik tot die verbetering van ons kerksang sal lei, want van 'n behoorlik toegeruste en toegewyde orrelis mag ons met reg verwag dat hy, met medewerking van die predikant en van die kerkraad-en hierdie medewerking moet hulle geredelik verleen! - dat die orrelis dan daar na sal strewe om die gemeentelike sang tot eer van God op hoër peil te bring. Hoe dit gedoen moet word, is hier nie ter sake nie. ${ }^{17}$ )

Dit val nou wel nie onder die gewone, regstreekse pligte van die orrelis nie, maar dit verdien tog aanbeveling dat waar dit prakties uitvoerbaar is, die orrelis in samewerking met die kerkraad geleenthede sal skep om die jong lidmate van die gemeente 'n bietjie onderrig en voorligting te gee in verband met die kerklied en kerkmusiek. Dit sal die waardering hiervoor in die gemeente seer seker ten goede kom. Ek maak my nie aan oordrywing skuldig nie as ek vasstel, dat die liefde vir die gewyde sang onder ons in die loop van die tye grotendeels weggesterwe het en dat daar maar betreklik min lede van die kerk is wat 'n waarderende oor vir kerkmusiek het. Miskien kan ons orreliste met die betrokke kerkrade planne beraam om in hierdie opsig die nodige opvoedingswerk te verrig, en ek dink dat ons Jeugvereniging hiervoor graag opening sal wil bied. In elk geval is dit 'n saak wat ons aandag verdien.

Volledigheidshalwe wil ek hier byvoeg dat, soos reeds geblyk het, die erediens met die votum begin en met die uitspreek van die seënbede eindig. Wat daarbuite val, behoort nie in eintlike sin tot die erediens nie. Daarom is dit so jammer dat die kollekte, of om dit sy regte naam te gee: die diens van die barmhartigheid, wat 'n wesenlike bestanddeel van die erediens vorm, nà die uitspreek van die seën opgeneem word. Hierdeur word dit buite die sfeer van die erediens geplaas, en ten onregte. So val dan ook die voor-en die naspel van die orrelis, d.w.s. wat hy voor die aanvang van die diens en na die seën speel, buite die eintlike erediens, maar vir praktiese doeleindes sluit ek dit by die erediens in. Ek het soëwe gewag gemaak van die stukke wat

16) „Wij hebben (gelukkig!) gemeentegezang; maar waartoe dat wanluidend gemeentegeschreeuw?" VAN OOSTERZEE, a.w., bls. 36.

17) Bevordering van sang by die huisgodsdiens. Meer sang op die Sondagskool. Sangoefening b.v. voor die aanvang van 'n aanddiens. Sangdienste. 'n Koor wat die psalm- en gesangmelodieë instudeer en leiding aan die gemeentesang gee. Vgl. VAN Oosterzes, a.w., bls. 78. Intussen moet dit m.i. betreur word dat die sing van lang en kort note in onbruik geraak het; dit bevorder, soos VoETIUs tereg opmerk, die skoonheid van die kerklied (BARGER, a.w. bls. 59), ook die lewendigheid. 
die orrelis speel. Die keuse van die musiek waartoe die orrelis hom by die erediens moet beperk, is hier nie ter sake nie. Bowedien het ek, hoewel ek my nie bekwaam ag om gesaghebbende advies in verband met hierdie aangeleentheid te gee nie, tog reeds, dink ek, genoegsame aanduiding gegee wat die aard van die stukke moet wees wat toelaatbaar is. Alle religieuse musiek is nog nie kerkmusiek nie ${ }^{18}$ ) en as die orrelis in veilige vaarwater wil bly, sal hy goeddoen om bedagsaam te wees met betrekking tot wat hy ten gehore bring. Hierby kom dat die gewoonte van sommige orreliste om, soos DR. CILLIÉ dit êrens uitdruk, ,allerlei toere op die orrel uit te voer" moet beslis afgekeur word. ${ }^{19}$ ) Ek sou in ernstige bedenking wil gee dat daar van bevoegde sy aan ons orreliste voorligting gegee sal word in verband met die vraag wat.eintlik onder die term ",kerkmusiek" verstaan moet word, want ait kom dikwels voor dat ons in die kerk musiek hoor wat wel die gehoor streel, maar tog nie kerkmusiek in die strenge sin van die woord is nie. Verder verdien dit aanbeveling, en ek wil dit graag onderstreep, dat kerkrade van tyd tot tyd uit hulle fondse ' $n$ bedrag beskikbaar stel vir die aankoop van geskikte musiek vir die orrelis. Daar is orreliste wat, ek vrees meer uit gemaksug as uit ander oorweginge, ' $n$ bepaalde lys van stukke daarop nahou, waaruit hulle Sondag na Sondag met voorbeeldige reëlmatigheid kies. Dit laat 'n mens aan die eentonige spyskaart van 'n plattelandse losieshuis dink. Nou spreek dit vansclf, as die orrelis hom nie die moeite en opoffering getroos om getrou te oefen nie, kan hy ook nie iets nuuts lewer nie. Ek raak miskien 'n gevoelige punt aan, maar dit moet my tog van die hart, $\mathrm{nl}$. dat ons orreliste oor die algemeen te weinig oefen, terwyl hulle belangrike aandeel in die erediens vir hulle genoegsame besieling moes wees tot die lewering van die beste waartoe hulle in staat is. Ek bring die opmerking van HUYGENS weer in herinnering, nl. dat die orrelis nie net die stem van die gemeente nie, maar ook die hart van die gemeente moet help berei vir die eerbiedige aandag wat die verkondiging van die Woord vereis.

En dit is sekerlik ' $n$ heerlike voorreg om dit te mag doen! Maar nogeens, dit vereis studie en oefening. Dit lê immers voor die hand dat daar nie besieling en wyding van die orrel kan uitgaan as die orrelis Sondae voor die orrel gaan sit sonder voorbereiding nie. Om 'n stuk tegnies onberispelik te speel is nie voldoende nie. Die orrelis moet

18) „Het spreekt vanzelf, dat de muziek, die in den eeredienst wordt gebruikt, een eigen stijl, een eigen karakter moet hebben dat door de aard van den dienst en de historische ontwikkeling word bepaald. Kerkmuziek is niet hetzelfde als religieuse muziek," VAN DER LEEUW, a.w. bls. 444.

19) VAN OOSTERzEE vestig tereg die aandag daarop "dat e $\mathrm{n}$ gebrekkig, smakeloos orgelspel de stichting maar al te vaak veelmeer belet, dan verhoogt," a.w. bls. 45 . In 1947 het STEVE DE VILLIERS reeds geskrywe: „Daar bestaan nog behoefte in ons kerke aan e $\epsilon$ nvoudige orrelmusiek wat op ons Psalms en Gesange gebaseer is, en van ons komponiste kan gerus in hierdie rigting dink," gesit. persartikel. 
hom deur oefening in die gees van die stuk (ook van die psalm of gesang) inlewe en die boodskap wat daarin skuil, met die nodige gevoel vertolk. Tereg word die orrel die koning onder die instrumente genoem, maar dikwels word koningsmoord gepleeg, en dit nog wel by geleenthede wanneer die tone van die orrel die lof van God moes uitjubel!

Ek het nou taamlik uitgewei oor wat van die orrelis verwag word. Daar is egter meer. En dit geld die predikant en die kerkraad. Ek vrees dat hulle, weliswaar meer uit onnadenkendheid as andersins, skromelik versuim om die orrelis af en toe met 'n woordjie van waardering te bemoedig. Ek weet wel dat dit nie die bedoeling van die orrelis is om die lof van mense in te oes nie, maar niks mensliks is ook die orrelis vreemd nie, en as hy darem die bewys het dat sy werk op prys géstel word, dat daar ten minste belangstelling van die kant van die predikant en van die kerkraad daarin getoon word, al mag dit soms ook wel by wyse van vriendelike kritiek wees, sal dit baie daartoe bydra om hom te besiel om na hoër hoogtes te strewe. Die orrelis mag in elk geval nie die gevoel kry dat hy 'n hulpdiens verrig wat net so wel gemis kan word nie.

Die orrelis tree in die reël ook by huweliksinseëninge op. Nou is dit ' $n$ feit dat die gemeente aan 'n huweliksinseëning ten onregte nie die karakter van 'n erediens toeken nie, met die gevolg dat daar vryhede geneem word wat dikwels baie ongepas en selfs onstigtelik is. Ek dink veral aan die onoordeelkundige keuse van die sangstukke wat meermale by so 'n geleenthid die bruidspaar toegesing word en waarteen ek reeds in "Die Hervormer" ernstige beswaar gemaak het, maar daar was nie die minste reaksie nie, sodat my stem blykbaar soos dié van een was wat in die woestyn roep. Dit sou onbillik wees om die blaam op die orrelis te lê, of selfs te verwag dat hy op eie verantwoordelikheid hierdie misstand moet teengaan. Die inisiatief moet in die eerste plek van die kerkraad uitgaan, want ook hierdie diens, hoewel dit nie besef word nie, staan onder die amptelike toesig van die kerkraad. Hierdie liggaam waarvan die predikant die voorsitter is, moet met die orrelis 'n plan beraam om beleidvol maar beslis ' $n$ einde te maak aan hierdie onstigtelike insluipsels in die huis van die Here en iets positiefs in die plek daarvan die lustige sangers aanbeveel, afgesien nou nog van die belangrike vraag of solosang in die erediens wel op sy plek is! Ek sê ,iets positiefs", want, helaas! ons Afrikaanse Psalm - en Gesangboek is brandarm aan gepaste liedere vir 'n huweliksinseëning, en dis 'n gebrek hierdie wat ons wel diep mag betreur. Prof. VAN SELMS het in 'n voortreflike artikel in die jongste Almanak o.m. hierop gewys. Ons kerk verkeer dan ook wat dit betref in 'n toestand van armoede wat moeilik verantwoord kan word. Intussen kan Ges. 263 uit die Nederlandse Psalm- en Gesangboek uitnemend 
diens doen. Hoe verhewe en stigtelik klink hierdie lied, hierdie innige en vrome toebidding van die seën van God op die bruidspaar, bo die inhoudlose en soutlose sentimentele liedjies wat ons in die reël moet aanhoor en wat sekerlik nie in die kerk tuishoort nie. Ek haal die eerste en die laaste vers van hierdie mooi lied aan:

\author{
U zeegne God, \\ Hij stell ' $u$ tot een zegen! \\ Gezegend zij uw hoofd, uw hart, uw wegen, \\ uw aardsch, uw eeuwig lot! \\ $O$ God verhoor \\ en schenk ons onze bede! \\ Toon hun Uw gunst, doordring hen van Uw vrede, \\ licht met Uw licht hen voor!
}

Daniël F. Erasmus.

Ventersdorp, 15 April 1953. 